\title{
Research on Curriculum Development of School-enterprise Cooperation in Mechanical Major
}

\author{
WANG Le \\ Baicheng Normal University, Baicheng, 137000, China \\ email: 1421464748@qq.com
}

Keywords: Mechanical major, School-enterprise Cooperation, Curriculum Development

\begin{abstract}
Mechanical major is a very practical subject and in its teaching practice that is of great practical significance to actively carry out cooperation between schools and enterprises. The in-depth and effective promotion of school-enterprise cooperation can enhance the practical ability of students majoring in mechanical engineering, cultivate high-level applied talents conforming to the social needs and development, and also promote the innovation and development of mechanical major. In the process of school-enterprise cooperation in mechanical engineering, curriculum development is very critical. Scientific curriculum development can effectively and effectively improve the overall teaching level of mechanical engineering, but also give full play to the advantages of school-enterprise cooperation.
\end{abstract}

\section{Introduction}

In the teaching practice of mechanical major, while the traditional teaching mode also pay attention to the organic combination of theory and practice of learning, but the influence and restriction of realistic environment makes the overall teaching level of the mechanical major is not high, especially its curriculum setting is more prominent with serious problems. The curriculum setting of mechanical major is relatively old and does not meet the development needs of mechanical major as well as the social practice requirements of students majoring in machinery, and at the same time the adjustment of curriculum has a certain lag. Problems of curriculum setting in mechanical major seriously restrict the overall optimization of teaching level of mechanical major and the further advance of school-enterprise cooperation in mechanical major. Therefore, combining with the teaching practice of mechanical specialty, it can enhance the overall teaching level and quality of mechanical major that optimizing the cooperation efforts to expand the depth of cooperation, creating the professional courses to meet the characteristics of school-enterprise cooperation.

\section{The Status and Development Necessity of Curriculum of School-enterprise Cooperation in Mechanical Major}

Mechanical engineering is a very practical subject and the social demand for mechanical majors mainly focus on their practical skills, which is also the basic starting point and goal of mechanical major teaching. The mechanical major although has actively promoted the school-enterprise cooperation model, but In contrast with the development of school-enterprise cooperation like a raging fire, curriculum development is not scientific and perfect. The current course system can not meet the requirements of deepening School enterprise cooperation, which seriously has restricted the quality of school-enterprise cooperation[1].

The Status of Curriculum of School-enterprise Cooperation in Mechanical Major. In the teaching practice of mechanical major, the traditional campus practice or lower-level off-campus internship, can not enhance students' occupation ability comprehensively and systematically, and achieve effective docking of students' practical ability and occupation ability. Especially, the curriculum system in mechanical major do not stand out the social attribute and the attribute of the enterprise of mechanical major, and the curriculum is relatively closed and rigid, which is a serious problem in the teaching process of mechanical specialty, and the main reason for students practice literacy relatively low majoring in mechanical engineering[2]. In the teaching practice of 
mechanical specialty, it can not only promote the further development of cooperation, but also improve the students' occupation accomplishment that actively carrying out school-enterprise cooperation, combining the model and characteristics of school- enterprise cooperation to deepen the curriculum design and development and creating new curriculum with the cooperation system. But the current curriculum of school-enterprise cooperation is still based on traditional curriculum standards as the leading, in the process of in-depth school-enterprises cooperation, only the combination of theory and practice, that is to say that the school teachers are responsible for explaining the theory and explain the simple practice skills, and enterprise personnel responsible for the actual experience and skills, the superficial cooperation is really difficult to enhance the students' practical ability and optimize the students' occupation accomplishment.

The Development Necessity of Curriculum of School-enterprise Cooperation in Mechanical Major. School-enterprise cooperation is a systematic process of practice, in mechanical teaching, actively carrying out school enterprise cooperation can achieve a scientific mechanism for co culture of schools and enterprises, and contribute to the practical ability and enhance the ability of students majoring in mechanical occupation. But the further development of school-enterprise cooperation, reasonable design and development based on the curriculum system, only according to the curriculum content, can bridge the gap between school education and enterprise education. Therefore, in the process of cooperation, the development of the characteristic curriculum system is very necessary.

Docking of the curriculum standards and the occupation standard. In the process of school-enterprise cooperation, through the development and construction of curriculum system, curriculum standard can be effective docking with the occupation standard. Professional curriculum standard is the main reference of mechanical professional teaching, curriculum standard is to proceed from the students a comprehensive and systematic study of mechanical professional knowledge system, which have a certain standard. But the mechanical major is a dynamic and social one, change and adjustment of social demand, has a larger role for the mechanical professional teaching goal. In the school-enterprise cooperation, the rigid curriculum standard, will be difficult to meet the actual needs of the enterprise in the process of cultivating talents. Therefore, through the development and design of curriculum, curriculum standard can be ensured to fully dock with the professional standards, industry standards, enterprise standards docking, that is helpful to cultivate the talents with machinery for enterprises[3].

Docking of the teaching process and the production process. In the process of school-enterprise cooperation, the curriculum design and development can promote the docking of teaching process and the production process. The traditional teaching mode, the teaching process and the production process are separated, which easily lead to closure of the teaching process. Students receive education of mechanical major in the school, because the actual production practice course and the enterprise is out of touch, students cannot use the theoretical knowledge and practical skills in the production process, that is not only easy to reduce the enterprise trust to mechanical professional students, will but also affect the mechanical majors employment rate. In the propulsion process of school-enterprise cooperation of mechanical major, combined with the characteristics of schoolenterprise cooperation, actively developing implementation of curriculum, innovating curriculum system and optimizing teaching contents can be fully break closure of the classroom teaching, but also can effectively link between the enterprise education and school education, and make the production process and teaching process be fully effective docked.

\section{The Safeguard Mechanism of Curriculum of School-enterprise Cooperation in Mechanical Major}

The practice of professional mechanical and occupation in the process of cooperation based on mechanical professional in constructing the characteristic curriculum system, can help enterprise cooperation machinery deeply and continuously, but also can improve the mechanical professional students' overall ability of practice. But the process of cooperation, the scientific and comprehensive safeguard mechanism is needed to ensure curriculum development to be accurate and effective, in 
order to effectively improve the mechanical professional teaching level[4].

Enhance the Level of Curriculum Development Comprehensively based on the Curriculum Development Organization. In the curriculum development of school-enterprise cooperation in mechanical major, in order to ensure the effectiveness of curriculum development, it is necessary to establish a scientific guarantee mechanism of curriculum development organization to enhance the efforts and the quality of curriculum development. Therefore, in the curriculum development, it is needed to fully combine with the teaching characteristics of mechanical major and social needs, and focus on the skills of the students demand for machinery enterprises to adjust and optimize the curriculum, so curriculum development must have the characteristics of the occupation to fully enhance the connection between the workshop and school curriculum. It can protect the curriculum set up directly for enterprises and the development of students that setting up a steering committee of the professional curriculum development, providing technical guidance for curriculum development by business experts, adjusting structure, regulation of curriculum content, implementation process and talents information, new technology information. At the same time, in the process of curriculum development, it is necessary to select the discipline responsible person combined with various majors, who collect the advice of teachers and business experts for comprehensive planning layout and scientific adjustment direction, so as to guarantee the rationality and scientificity of the curriculum development. In addition, in the process of curriculum development, the teachers should also be included in the curriculum development system, who are the direct implementation of occupation education and have a certain right to speak for the students' learning needs and characteristics. The school-based textbooks based on school-enterprise cooperation are taught to students ultimately by those teachers[5].

Seek the Hardware Foundation for Curriculum Development, Enhance the Efficiency of Science Curriculum Development. In the process of school-enterprise cooperation of mechanical major, based on optimizing the direction of school-enterprise cooperation and students' occupation literacy, the material foundation and hardware protection are also needed to actively seek in the process of curriculum development. On the one hand, as the main implementation of curriculum development, the mechanical professors and teachers of schools must pay attention to deepen the theoretical basis of its own, be closely combined with the change and development of social demand, and closely fit the mechanical professional development direction, but also need to use the school's training base or laboratory to evidence the school-based teaching materials, who should strengthen their own practical cognition and ensure the effectiveness and practicability of curriculum development at the same time. On the other hand, in the process of curriculum development, curriculum editors should listen to various opinions and actively seek the support of the enterprise. The curriculum development needs through repeated verification, especially the verification of business line practice. Therefore, in the process of curriculum development, enterprises can not play the role of a "bystander", but should be fully involved to provide the corresponding equipment for curriculum development and optimize the utility function of curriculum development.

\section{The Content of Curriculum Development of School-enterprise Cooperation of Mechanical Major}

In the process of school enterprise cooperation in mechanical specialty, the realization of scientific curriculum development needs not only the scientific guarantee mechanism, but also the accurate delineation of the content of curriculum development, so as to enhance the effectiveness of curriculum development. The content of curriculum development not only need to meet the needs of students development, but also meet the students occupation accomplishment needs of business. Therefore, based on the school-enterprise cooperation, in the process of curriculum development of mechanical major , the following points need to be focused on:

Identify the Tasks. In the process of curriculum development of school-enterprise cooperation of mechanical major, it need take a typical task as the center that actively developing curriculum resources and setting up reasonable curriculum. In the practical curriculum development, the highly 
integrated curriculum content should be based on the purpose of the project teaching method and scientifically define the related content with a typical task as the center. On the one hand, the decision of the tasks based need base on the development trend of mechanical engineering, deeply study mechanical professional social trends and future job requirements, and combine with the the realistic environment in school-enterprise cooperation. The task should highlight the property of times, practicality and reality, so that students in the task of learning, can be able to use the knowledge they have learned to take the initiative to explore, in the process of exploring the task, analyzing task and solving task, students will form a comprehensive thinking ability, and actively applied this ability to solve the task. On the other hand, in the process of curriculum development of school enterprise cooperation in mechanical engineering, based on task, the proportion of theoretical courses and practical courses should be adjusted to highlight the practical ability of the students. For example, in the teaching of mechanical cutting tasks, teachers should reduce the appropriate time course theory, as far as possible fit the theory teaching into the practice process in the school training base, that can prolong itself practice teaching time, but also help to improve the students' practical ability.

Identify the Curriculum. In the process of curriculum development of school-enterprise cooperation of mechanical major, the students' knowledge system and the future development direction must be considered reasonably to determine the course of study and enhance the teaching aim. The category of mechanical major is more systematic, students through the courses study of mechanical major in school stage, in the future work more detail field will be discussed. This division of field is related to the interests of the students, but also with the cognitive ability of students on the professional domain. In the process of curriculum development, the courses should be classified should be combined with the task to do detailed planning and arrangement based on division of professional field and should meet the needs of the students. At the same time, curriculum development is the starting point, students' learning input and cognition is the goal of curriculum development. Therefore, in the process of teaching of mechanical specialty, teachers should cultivate the students' practical ability, encourage students to use the knowledge system and the inherent theory to actively dedicate themselves to the research of mechanical professional courses. The understanding and appreciation of students for the course study, and students' interest and commitment to learning, is directly related to the teaching level of mechanical major. Therefore, in the teaching practice of mechanical specialty, teachers can make comprehensive use of situational teaching method, information teaching and practice teaching and other multiple teaching methods.

Develop the School-based Teaching Materials. Many practical operation of mechanical engineering major, although with certain norms, often formed its own unique pattern in the specific application process of enterprise. At the same time, the teaching practice of mechanical specialty in different schools also have their own characteristics. Therefore, to strengthen the relationship with enterprise practice and more effectively improve the use rate of the school-based teaching materials, in the process of curriculum development, the school-based teaching materials must be payed attention to rational development according to the characteristics and practice of the course. On the one hand, in the process of the development of school-based teaching materials, we should actively adopt "double responsibility system", the school teachers and business experts determine the curriculum content to effectively open classroom teaching conditions and match the development and system of the new curriculum textbook series, fully enhancing the overall utilization of school-based teaching materials. On the other hand, the development of school-based teaching materials also need to fully integrate the post demand and the future development direction of students to match the corresponding knowledge system, fully meet the needs of knowledge system for post service, scientifically and comprehensively improve students' occupation quality, and enrich students' post literacy, so that students in the next post internship or after entering the post can quickly adapt to the job. 


\section{Conclusion}

Practicality and professionalism of mechanical major requires in the teaching practice of mechanical specialty that school-enterprise cooperation must be actively carried out. However, deeply and comprehensively promoting the cooperation between enterprises and school cannot do without scientific and reasonable curriculum development and design. In the process of curriculum development, it is necessary to fully understand the necessity of curriculum development and establish the safeguard mechanism to scientifically and reasonably ensure the content of curriculum development.

\section{References}

[1] LIU Huifang. The curriculum development of mechanical major based on school-enterprise cooperation[J].Occupation,2015(32):79-79.

[2] ZHOU Dengpan. Study on the safeguard mechanism of curriculum development of school-enterprise cooperation in higher vocational colleges[J]. Mechanical occupation education, 2015(6): 32-33.

[3] LIU Tao, WANG Dan. Study on the curriculum development of school-enterprise cooperation in higher vocational colleges[J]. Liaoning Higher Vocational Technical Institute Journal, 2015(6): 32-33.

[4] LIU Hequn, CHEN Xiaolong. Research on the interactive pattern of curriculum development of school-enterprise cooperation in higher vocational colleges[J]. Vocational and Technical Education, 2017, 3(05): 327-327.

[5] LI Yadong, SUN Lili. Study on the curriculum development of school-enterprise cooperation in precision machinery technology major[J]. Education, 2017,3 (05):327-327. 